\title{
Gold nanoparticle-based strip sensor for multiple detection of twelve Salmonella strains with a genus-specific lipopolysaccharide antibody
}

\author{
Wenbin Wang, Liqiang Liu, Shanshan Song, Liguang Xu, Hua Kuang*, Jianping Zhu and Chuanlai Xu
}

\begin{abstract}
In this study, an innovative competitive immunochromatographic strip sensor was developed for rapid detection of Salmonella based on a genus-specific antilipopolysaccharide (LPS) monoclonal antibody (mAb) and the heterogeneous coating antigen of a LPS-bovine serum albumin conjugate. Gold nanoparticles labeled anti-LPS $\mathrm{mAb}$ specifically reacted with the conserved outer core of the Salmonella LPS in the sample and the color formed on the $\mathrm{T}$ line was negatively correlated with the number of Salmonella cells. The sensitivity of Ra mutant LPS (without $O$-specific chains but has the conserved outer core) was 25 $\mathrm{ng} \mathrm{mL}^{-1}$, which explained the detection of Salmonella at the genus level. Based on the gray values on the test line, the limit of detection of Salmonella was $10^{3}$ colony-forming unit (CFU) for all twelve typical strains of Salmonella. The analysis of common Gram-negative and Gram-positive bacteria demonstrated that the strip assay was specific to Salmonella. A milk sample test showed that Salmonella at a low level (1-5 CFU $\mathrm{mL}^{-1}$ ) was detected without complex biochemical confirmation steps, sophisticated instruments and professional training.
\end{abstract}

Keywords: Salmonella, lipopolysaccharide, monoclonal antibody, immunochromatographic strip, Au nanoparticles

\section{INTRODUCTION}

Food poisoning and foodborne diseases, which tend to occur in a wide area and lead to gastrointestinal disease, are a major concern worldwide [1,2]. Among the foodborne pathogens related to poisoning, Salmonella is reported to be the leading cause of poisoning in many countries including China [3,4]. Salmonella is a genus of Gram-negative bacteria that has more than 2000 pathogenic serotypes including the well-known serotypes S. typhimurium and
S. enteritidis $[5,6]$. The main antigens of Salmonella are lipopolysaccharide ( $\mathrm{O}$ antigen), flagellin ( $\mathrm{H}$ antigen), and capsular polysaccharide (Vi antigen). The difference in $\mathrm{O}$ antigen and $\mathrm{H}$ antigen between strains is the basis for Salmonella serotyping [7]. The standard detection method for Salmonella is culture-based and requires multiple steps of enrichment and biochemical confirmation. The results are usually obtained after $4-7 \mathrm{~d}$. Therefore, rapid detection methods are highly desirable to overcome the disadvantages of time-consuming and labor-intensive traditional methods.

Currently, polymerase chain reaction (PCR)-based methods, immunoassays, isothermal amplification methods, and aptamer-based methods have been developed for the rapid detection of Salmonella. PCR-based methods including real-time PCR, which are robust but rely on sophisticated instruments and professional training, are more suitable as confirmation methods in the laboratory than as pre-screening tools for large samples $[8,9]$. Compared with PCR, nucleic acid hybridization including loop-mediated isothermal amplification is portable, rapid and easy to operate [10]. However, the dependence on a relatively high temperature $\left(63^{\circ} \mathrm{C}\right)$ and DNA extraction step still limit the practical application of these methods $[11,12]$. Due to the specificity of the selected aptamer, aptamer-based sensors are mainly used for rapid detection of common serotypes such as $S$. typhimurium and $S$. enteritidis, rather than detection of the genus $[5,13,14]$. Immunoassays based on the specific antigen and antibody reaction have been widely used in Salmonella detection either with the classic enzyme-linked immunosorbent assay (ELISA) [15-18] or novel nanomaterials-based biosensors

State Key Lab of Food Science and Technology, Jiangnan University, and School of Food Science and Technology, Jiangnan University, Wuxi 214122, China

*Corresponding author (email: kuangh@jiangnan.edu.cn) 
[19-22]. However, due to the drawbacks of multiple steps and high-cost of these methods there is a huge demand for a low cost, portable, rapid and stable method.

The lateral flow-based immunochromatographic strip sensor, which takes advantage of the stable immunoreaction of the monoclonal antibody $(\mathrm{mAb})$ and the rapid chromatographic procedure, is a very powerful point of care test for pathogens, and environmental pollutants in food samples [23-26]. Some immunochromatographic strip assays based on serotype specific or serogroup specific mAbs have been used to detect common Salmonella strains including S. typhimurium [6,27,28], S. enteritidis [29], S. choleraesuis [30] and S. typhi [31]. Bautista et al. [32] reported the detection of 19 out of 22 tested Salmonella strains using a commercial immunochromatographic strip. The detection of Salmonella at the genus level with the traditional sandwich-based strip assay is mainly limited by the preparation of a genus-specific antibody and the effective pair that works on the strip test.

Therefore, we developed a novel competitive immunochromatographic strip sensor based on a genus-specific anti-lipopolysaccharide (LPS) $\mathrm{mAb}$ and the heterogeneous coating antigen of the LPS-bovine serum albumin (BSA) conjugate, to overcome the difficulties associated with rapid detection of Salmonella at the genus level. The $\mathrm{mAb}$ against the conserved outer core of the Salmonella LPS was prepared with the LPS-BSA conjugate as the immunogen for BALB/c mice. Furthermore, our novel strategy eliminated the need for paired $\mathrm{mAbs}$ based on the competition of Salmonella and the coating antigen with the gold nanoparticle ( $\mathrm{Au} \mathrm{NP}$ ) labelled anti-LPS mAb. This strip sensor was evaluated using twelve typical Salmonella strains with different $\mathrm{O}$ antigens and eight common strains of Gram-negative and Gram-positive bacteria. In addition, milk samples contaminated with a low level of four common Salmonella serotypes were analyzed after 12 h enrichment.

\section{EXPERIMENTS}

\section{Salmonella strains and growth conditions}

The strains of Salmonella spp. used in this study are listed in Table S1. Non-Salmonella strains included Staphylococcus aureus (ATCC 29213), Listeria monocytogenes (ATCC 19111), Escherichia coli O157:H7 (E. coli O157:H7, CICC 21530), E. coli O6 (ATCC 25922), Cronobacter sakazakii (ATCC 29544), Vibrio parahemolyticus (CMCC 20017), Campylobacter jejuni (ATCC 33291) and Campylobacter coli (ATCC 43478). Campylobacter jejuni and Campylobacter coli were cultured in Brain-Heart Infusion broth
(Oxoid, Basingstoke, $\mathrm{UK}$ ) at $37^{\circ} \mathrm{C}$ for $2-3 \mathrm{~d}$ in a micro-aerobic environment $\left(4 \% \mathrm{O}_{2}, 10 \% \mathrm{CO}_{2}\right.$ and $\left.86 \% \mathrm{~N}_{2}\right)$ in a three gas incubator (Binder CB210, Tuttlinger, Germany). Vibrio parahemolyticus was cultured in tryptone soya broth (Oxoid, Milan, Italy) with $1 \% \mathrm{NaCl}$ at $37^{\circ} \mathrm{C}$. The other bacteria were cultured overnight at $37^{\circ} \mathrm{C}$ in Brain-Heart Infusion broth.

\section{Production of genus-specific LPS monoclonal antibody}

S. typhimurium LPS (Sigma, St Louis, MO, USA) was conjugated to BSA using the active ester method [33] to prepare the immunogen. Briefly, $1 \mathrm{~mL}$ of LPS $\left(5 \mathrm{mg} \mathrm{mL}^{-1}\right.$, water) was first added with borate saline buffer $\left(0.2 \mathrm{~mol} \mathrm{~L}^{-1}, 50\right.$ $\mu \mathrm{L})$ to maintain the $\mathrm{pH}$ at 5 and was activated with 1-(3-dimethylaminopropyl)-3-ethylcarbodiimide (1 mg, $N, N$-dimethylformamide) and $N$-hydroxysuccinimide (1 mg, water) at room temperature for $2 \mathrm{~h}$. Then, $100 \mu \mathrm{L}$ of BSA (50 mg mL $\mathrm{mL}^{-1}$, water) was added and the $\mathrm{pH}$ of the solution was adjusted to 9.0 with bicarbonate buffer $(0.05$ mol L $\left.\mathrm{L}^{-1}, 50 \mu \mathrm{L}\right)$. After overnight reaction, the solution was dialyzed.

BALB/c mice aged 6-8 weeks were immunized with the immunogen to produce the anti-LPS antibody. Spleen cells from the mice were then fused with $\mathrm{Sp} 2 / 0$ myeloma cells. After selection against Ra LPS which lost the O-specific chain but reserved the outer core structure from mutant $S$. typhimurium (Sigma, St Louis, MO, USA) and confirmation using Salmonella strains with different $\mathrm{O}$ antigens, cell lines with homogenous cross-reactivity within the Salmonella genus were obtained. The produced mAbs were purified using the caprylic acid-ammonium sulfate precipitation method. The half maximal inhibitory concentration (IC50) of the mAbs were characterized by indirect competitive enzyme-linked immunosorbent assay (IC-ELISA) [34].

\section{Au NPs labeled monoclonal antibody and coating antigens} $\mathrm{Au}$ NPs $(15 \mathrm{~nm})$ were synthesized by the classic citrate sodium reduction method [35]. The Au NPs and LPS $\mathrm{mAb}$ conjugates were prepared as follows: $1 \mathrm{~mL}$ of Au NPs was added to $7 \mu \mathrm{L}$ of $0.1 \mathrm{~mol} \mathrm{~L}^{-1} \mathrm{Na}_{2} \mathrm{CO}_{3}$ and the $\mathrm{pH}$ was adjusted to 7.5. Then, $10 \mu \mathrm{L}$ of the anti-LPS mAb (1 mg $\mathrm{mL}^{-1}$ ) was added to the Au NPs solution and reacted for 2 $\mathrm{h}$ at room temperature with gentle mixing. BSA $(50 \mu \mathrm{L}$ of a $100 \mathrm{mg} \mathrm{mL}^{-1}$ solution) was then added to the solution and reacted for another $2 \mathrm{~h}$ in room temperature to block the non-binding sites. Finally, the Au NPs-modified LPS mAb was centrifuged twice $(6000 \times \mathrm{g}, 20 \mathrm{~min})$ and preserved in $10 \mathrm{mmol} \mathrm{L}^{-1}$ PBS containing $0.02 \% \mathrm{NaN}_{3}$ at $4^{\circ} \mathrm{C}$ until use. 
The coating antigens of LPS and BSA conjugate were synthesized by the active ester method and the periodate oxidization method [36]. Briefly, $1 \mathrm{~mL}$ of LPS $\left(5 \mathrm{mg} \mathrm{mL}^{-1}\right.$, water) was oxidized with $75 \mu \mathrm{L}$ sodium periodate $(10 \mathrm{mg}$ $\mathrm{mL}^{-1}$, water) at room temperature for $30 \mathrm{~min}$ with magnetic stirring. Then, $100 \mu \mathrm{L}$ ethanediol $\left(0.16 \mathrm{~mol} \mathrm{~L}^{-1}\right.$, water $)$ was added and reacted for another $30 \mathrm{~min}$ to neutralize the excess sodium periodate. BSA ( $100 \mu \mathrm{L}$ of $50 \mathrm{mg} \mathrm{mL}^{-1}$, water) was then added and the $\mathrm{pH}$ of the solution was adjusted to 9.0 with bicarbonate buffer $\left(0.05 \mathrm{~mol} \mathrm{~L}^{-1}, 50 \mu \mathrm{L}\right)$. After 24 $\mathrm{h}$ reaction at room temperature, the solution was dialyzed with $10 \mathrm{mmol} \mathrm{L}^{-1} \mathrm{PBS}$ at $4^{\circ} \mathrm{C}$.

\section{Establishment of the competitive immunochromatographic strip sensor}

The prepared coating antigen $\left(1 \mathrm{mg} \mathrm{mL}^{-1}\right)$ and goat antimouse IgG antibody $\left(0.5 \mathrm{mg} \mathrm{mL}^{-1}\right)$ were sprayed onto the test line ( $\mathrm{T}$ line) and the control line ( $\mathrm{C}$ line) on the nitrocellulose (NC) membrane using a BioJet Quanti3000 dispenser. After air-drying at $37^{\circ} \mathrm{C}$ for $2 \mathrm{~h}$, the NC membrane was cut into strips ( $4 \mathrm{~mm}$ wide) with a CM4000 guillotine cutting module. The fabricated strips were stored with a desiccant at room temperature until use.

The analysis of Salmonella was as follows: a pure cultured Salmonella strain was boiled for $15 \mathrm{~min}$. The sample (100 $\mu \mathrm{L}$ ) was added to the solution and mixed with $7 \mu \mathrm{L}$ of the $\mathrm{Au}$ $\mathrm{NP}-\mathrm{mAb}$ probe and $43 \mu \mathrm{L}$ of suspension buffer $(10 \mathrm{mmol}$ $\mathrm{L}^{-1}$ PBS, $2 \%$ BSA, $0.1 \%$ Tween, $0.2 \%$ sucrose). The antigen-antibody reaction was allowed to continue for $5 \mathrm{~min}$ at $37^{\circ} \mathrm{C}$. The strip was then loaded and the results were judged with the naked eye after $10 \mathrm{~min}$. Weakend red color on the $\mathrm{T}$ line compared with that of the negative control indicated that the sample was positive for Salmonella. The same red color on the T line compared with that of the negative control indicated the sample was negative for Salmonella. Red band on the $\mathrm{C}$ line should present for both positive and negative sample. The visual limit of detection (vLOD) is defined as the lowest concentration of Salmonella that produces the color on the test line significantly weaker than that of the negative control $[23,37]$. The optical density of the test line was recorded with a strip reader.

Coating antigens, anti-LPS mAbs, and sample dilution buffer were successively optimized to improve the sensitivity of the competitive immunochromatographic strip.

\section{Sensitivity and specificity of the immunochromatographic strip sensor}

The sensitivity of the competitive strip was tested with Ra LPS and the twelve Salmonella strains which had different serogroups of $\mathrm{O}$ antigen. Ra LPS from Salmonella was serially diluted to $100,50,25,10,5 \mathrm{ng} \mathrm{mL}^{-1}$ and 0 with PBS (10 $\mathrm{mmol} \mathrm{L}^{-1}, \mathrm{pH} 7.2$ ) before analysis. The twelve pure cultured Salmonella strains were boiled and serially diluted to $10^{7}, 10^{6}, 10^{5}, 10^{4} \mathrm{CFU} \mathrm{mL} \mathrm{mL}^{-1}$, and 0 with PBS for determination. Specificity of the strip was evaluated using Gram-positive bacteria including Staphylococcus aureus and Listeria monocytogenes, and Gram-negative bacteria including E. coli O157:H7, E. coli O6, Cronobacter sakazakii, Vibrio parahemolyticus, Campylobacter jejuni, Campylobacter coli and $S$. enteritidis. The pure cultured strains as described above were boiled and diluted to $2 \times 10^{8} \mathrm{CFU} \mathrm{mL}^{-1}$ for the test.

\section{Milk sample detection using the immunochromatographic strip sensor}

A pure milk sample was purchased from a local market and confirmed to be free of Salmonella spp. by the culture-based method [38]. To simulate a real sample contaminated with a low level of Salmonella spp., the milk was individually spiked with fresh cultured S. paratyphi A, S. typhimurium, S. enteritidis, and $S$. arizona at 1-5 CFU $\mathrm{mL}^{-1}$ by serial dilution. The spike level and the original concentration of the culture $\left(10^{9}\right.$ to $\left.5 \times 10^{9} \mathrm{CFU} \mathrm{mL} \mathrm{mL}^{-1}\right)$ were further confirmed by the plate counting method. Then, $25 \mathrm{~mL}$ of the spiked samples were added to $225 \mathrm{~mL}$ buffered peptone water (Oxoid, Basingstoke, UK) and cultured at $37^{\circ} \mathrm{C}$ for $12 \mathrm{~h}$. Samples of the culture were boiled for $15 \mathrm{~min}$ before analysis with the immunochromatographic strip.

\section{RESULTS AND DISCUSSION}

\section{Principle of the competitive immunochromatographic strip} sensor

The principle of the immunochromatographic strip for detection of Salmonella spp. is shown in Fig. 1. The T line and $C$ line were coated with Salmonella LPS-BSA conjugate and Goat anti-mouse IgG antibody, respectively. When no Salmonella was present in the sample, the Au NPs labeled anti-LPS mAbs reacted with the LPS-BSA conjugate on the $\mathrm{T}$ line and the remainder was captured by the anti-mouse IgG antibodies on the $\mathrm{C}$ line. Red bands due to the Au NPs were observed both on the $\mathrm{T}$ line and the $\mathrm{C}$ line. When Salmonella was present in the sample, the Au NPs labeled anti-LPS mAbs first reacted with the LPS on the surface of Salmonella cells and then reacted with the $\mathrm{T}$ line and the $\mathrm{C}$ line. The color of the $\mathrm{T}$ line decreased at this time. The color intensity on the $\mathrm{T}$ line was negatively correlated with the amount of Salmonella in the sample. 


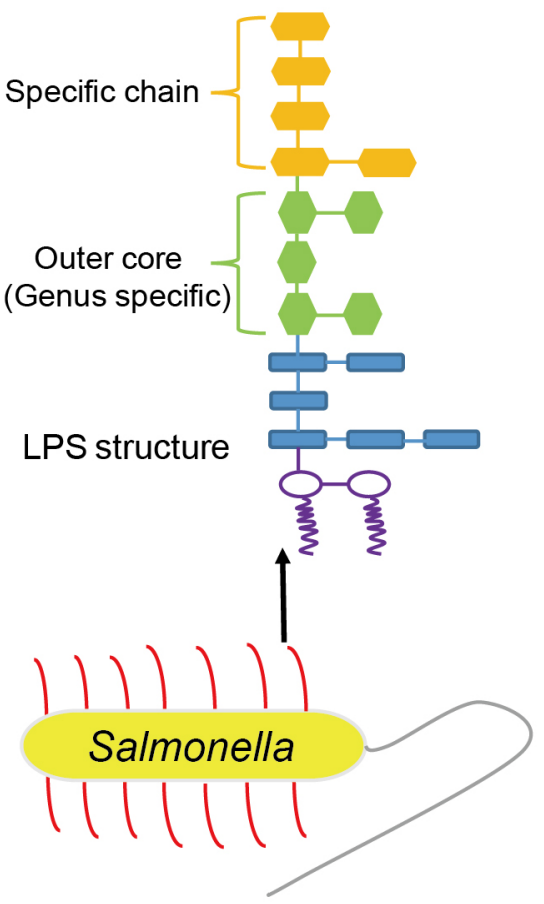

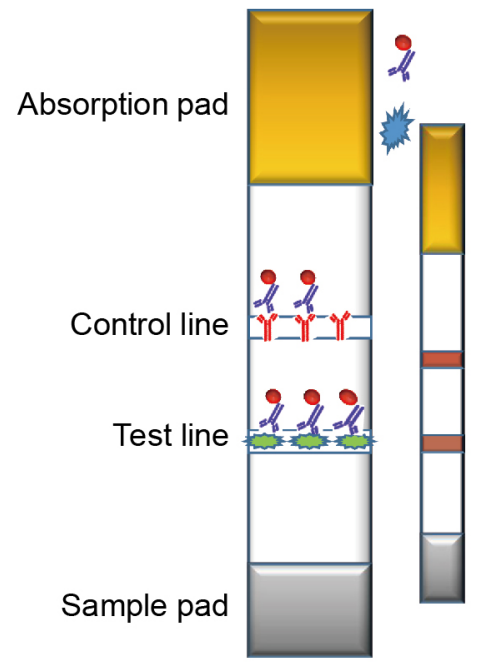

Sample without Salmonella

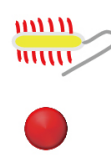

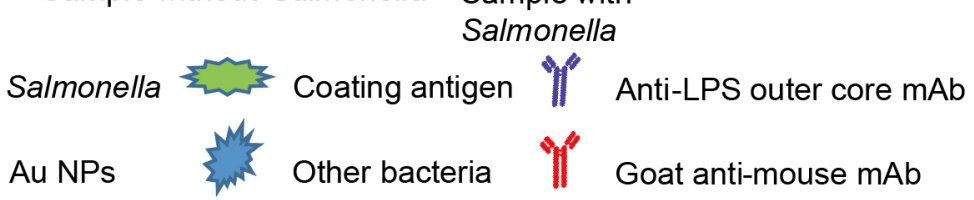

Figure 1 Scheme of the immunochromatographic strip sensor for Salmonella spp. Weakened red color on the Tline compared with that of the negative control and a red band on the C line indicated that the sample was positive for Salmonella.

Compared to the commonly used sandwich-based strategy $[39,40]$, this LPS $m A b$ and coating antigen-based paper sensor for competitive detection of Salmonella is innovative and greatly simplifies the development of the strip assay. This is because sandwich-based strategy usually needs two mAbs which must be both paired in ELISA and still work in lateral flow assay. In our previous work, we developed a sandwich ELISA based on a genus specific LPS mAb and the sensitivity was determined to be $10^{6} \mathrm{CFU} \mathrm{mL}^{-1}$ [36]. This indicated that sandwich based strip assay may not be suitable for this $\mathrm{mAb}$ because the detection limit of immunochromatographic strip is usually higher than ELISA. Furthermore, Compared with the insufficient cross-reactivity among Salmonella spp. in previous studies of the sandwich-based immuno-strip assay [28,31], using of the Salmonella -specific anti-LPS $m A b$ enabled the rapid detection of Salmonella at the genus level with broad cross-reactivity and high specificity.

\section{Optimization of the competitive immunochromatographic strip sensor}

The transmission electron microscopy (TEM) image (Fig. S1) shows that the synthesized Au NPs have uniform diameter $(15 \pm 2.82 \mathrm{~nm})$ and good dispersity. The ultraviolet-visible (UV-vis) spectra (Fig. S2) indicates the maximal absorbance of the Au NP red-shift from 520 to $526 \mathrm{~nm}$ af- ter the reaction with the mAb $5 \mathrm{H} 12$, which reflects the increased diameter caused by successful conjugation.

The coating antigen, anti-LPS $\mathrm{mAb}$ and sample dilution buffer significantly affected the performance of the strip and thus were optimized. First, the two prepared coating antigens of the LPS-BSA conjugates (Fig. S3) were evaluated using the anti-LPS mAbs. Fig. S4 shows that the color intensity formed on the $\mathrm{T}$ line with the homologous coating antigen synthesized by the active ester method is too strong and the color of the $\mathrm{C}$ line is very light. In contrast, the colors of the $\mathrm{T}$ line and $\mathrm{C}$ line with the heterogeneous conjugate synthesized by the periodate oxidization method are comparable. This is because the antibody affinity against the homologous coating is usually higher than the heterogeneous coating [41]. We chose the heterogeneous coating antigen by the periodate oxidization method for further study as moderate affinity was suitable for the competition between the sample and the coating antigen.

The anti-LPS $m A$ Abs were then tested with the competitive immunochromatographic strip with Ra LPS as standard. Fig. S5 shows that these anti-LPS mAbs reacted with the Ra LPS which retained the conserved outer core of Salmonella and clearly inhibited the color on the T line. Among these $\mathrm{mAbs}, 5 \mathrm{H} 12$ was selected due to complete inhibition of the color on the T line with $100 \mathrm{ng} \mathrm{mL}^{-1} \mathrm{Ra}$ LPS and relatively higher color intensity on the $\mathrm{T}$ line for the negative control. 
In addition, $10 \mathrm{mmol} \mathrm{L}^{-1} \mathrm{PBS}$ containing $3.3 \mathrm{~mol} \mathrm{~L}^{-1}$ ethylenediaminetetracetic acid (EDTA) and $0.1 \%$ Triton 100 was used as a sample dilution buffer to break the steric hindrance caused by the buried outer core structure in the inner side of LPS on the cell surface of Salmonella [42]. Fig. S6 indicates that the sample dilution buffer completely inhibited $10^{5} \mathrm{CFU}$ S. kentucky and no color was observed on the $\mathrm{T}$ line. In contrast, the color was still visible on the $\mathrm{T}$ line with PBS as the sample dilution buffer. This was because EDTA chelated the bivalent cations that can stabilize the micelle-like structure of LPS on the cell surface and Triton 100 is a mild surfactant that can improve the membrane permeability of the cell [43].

\section{Sensitivity and cross-reactivity of the immunochromato- graphic strip sensor}

Fig. 2a shows that the vLOD of Ra LPS using the immunochromatographic strip was $25 \mathrm{ng} \mathrm{mL}^{-1}$ and the IC50 of the $5 \mathrm{H} 12$ against Ra LPS in the IC-ELISA was $6.5 \mathrm{ng} \mathrm{mL}^{-1}$ (Fig. 2b). Ra LPS from S. typhimurium loses the repetitive O specific chain which has high diversity between different serogroups of Salmonella and retains the conserved outer core structure in Salmonella [18]. The sensitive detection of Ra LPS clearly indicated the mechanism involved in the detection of Salmonella.

To validate the sensitivity and cross-reactivity in the genus Salmonella, twelve strains belonging to serogroups O: 2, O: 4, O: 7, O: 8, O: 9 O: 3, 10 and IIIa were analyzed using the competitive immunochromatographic strip. Fig. 3a shows that all the tested strains including $S$. paratyphi A, S. agona, S. paratyphi B, S. typhimurium, S. thompson, S. blockley, S. kentucky, S. enteritidis, S. typhi, S. dublin, $S$. anatum, and $S$. arizona inhibited the color on the $\mathrm{T}$ line with an increasing number of Salmonella cells. The vLOD of these Salmonella strains was $10^{5} \mathrm{CFU}$, except for S. arizona with a vLOD of $10^{6} \mathrm{CFU}$. With the strip reader, area of the gray values on the $\mathrm{T}$ lines were recorded and plotted. Fig. $3 \mathrm{~b}$ indicate that the gray values decreased at $10^{3} \mathrm{CFU}$ for all the tested strains (5\%-30\%) except S. thompson $\left(10^{4} \mathrm{CFU}\right)$. The significant improvement of the sensitivity is due to the competitive scheme and the decrease of the gray value is more sensitive than the visual change of the color. These tested strains represent the typical serotypes of Salmonella (serogroup A, B, C, $\mathrm{D}$ and E) that lead to the majority of Salmonella-related foodborne diseases [44]. S. arizona is characterized by a special biochemical reaction (fermentation of lactose to produce acids and $\mathrm{CO}_{2}$ ) and unique outer core structure of the $\mathrm{O}$ antigen (IIIa) in the genus of Salmonella [45]. Unlike the $N$-acetyl-D-glucosamine on the outer core of the LPS in other Salmonella strains, the D-glucosamine in S. arizona was not $\mathrm{N}$-acetylated. The detection of S. arizona, although at a relatively higher vLOD, demonstrated the homogenous cross-reactivity in the Salmonella genus.

In the previous works, the majority of the reported ELISA and immunochromatographic strips were specific to only
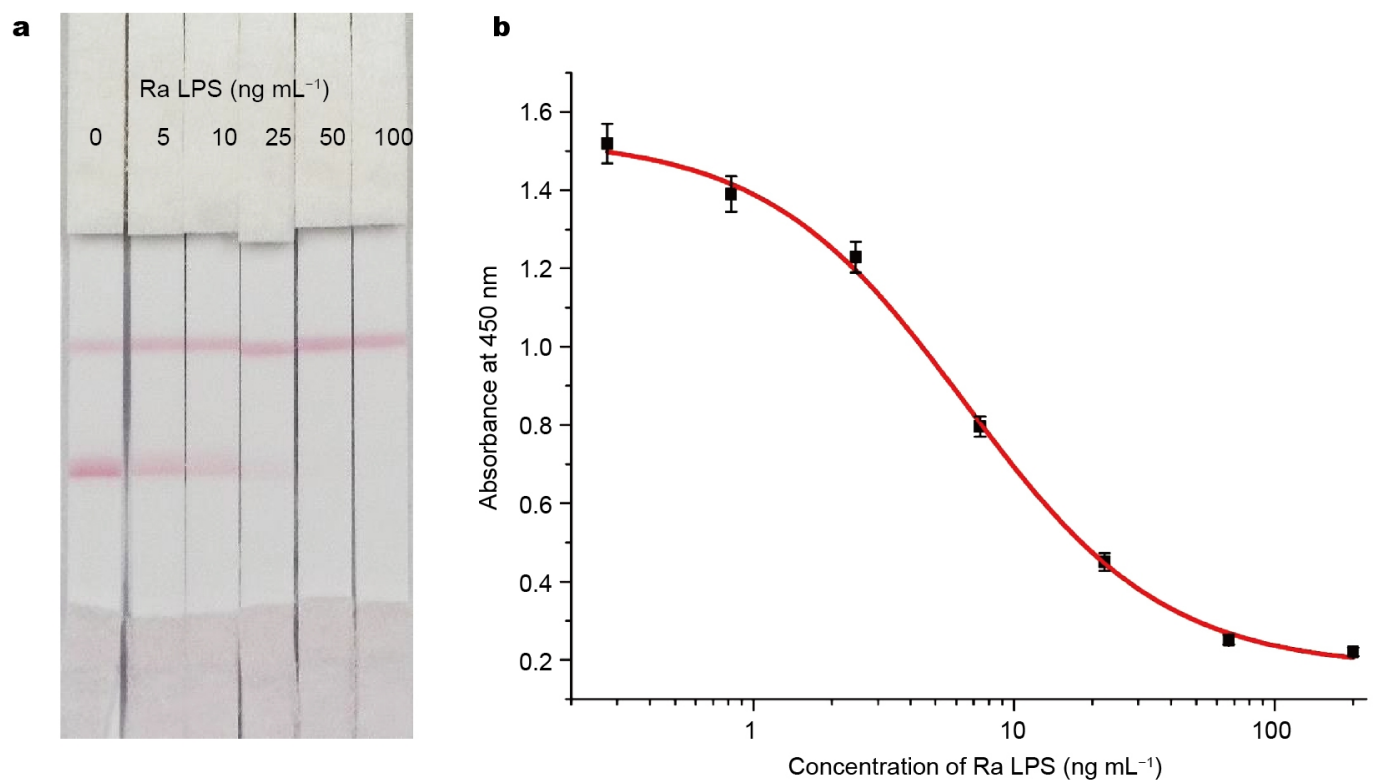

Figure 2 Detection of Ra LPS with the mAb 5H12 based competitive Immunochromatographic strip sensor (a). Standard curve of the competitive ELISA with the mAb $5 \mathrm{H} 12$ (b). 

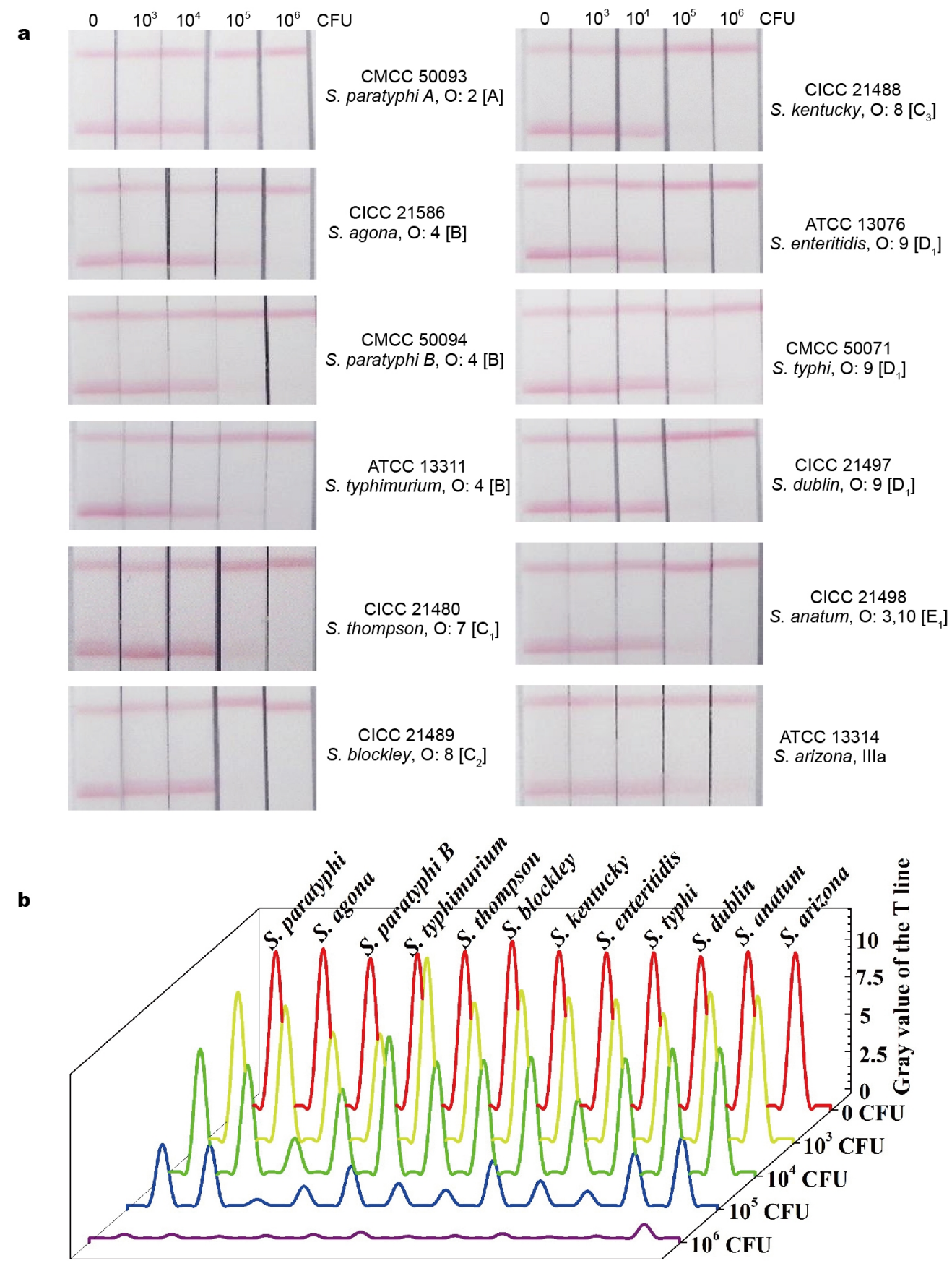

Figure 3 (a) Images of the Immunochromatographic strip sensor for detection of twelve typical strains of Salmonella; (b) gray values of the T lines for detection of the twelve typical strains.

one or two serotypes of Salmonella, with sensitivities ranged from $10^{3}$ to $10^{5} \mathrm{CFU} \mathrm{mL} \mathrm{m}^{-1}[15,31,46]$. Although the tests were very sensitive, the applications for detection of the genus of Salmonella were limited. The genus specific sandwich ELISA methods of Salmonella, reported by Wu et al. [36] and Choi et al. [42] respectively, all have a sensitivity of $10^{6} \mathrm{CFU} \mathrm{mL} \mathrm{m}^{-1}$. The lateral flow assay of Sal- monella developed by Bautista et al. [32] has a sensitivity

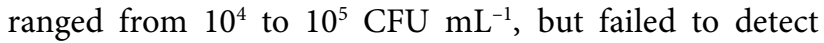
the $S$. worthington, S. choleraesuis var. kunzendorf, and $S$. johannesburg. Therefore, compared with the previous works, our paper sensor is both sensitive and accurate for the detection of Salmonella. The future of our work will focus on further improving the sensitivity of the Salmonella 
biosensor based on lanthanide $\left(\mathrm{Ln}^{3+}\right)$-doped nanoparticles [47], $\mathrm{ZnO}$ nanomaterials [48], and surface-enhanced Raman scattering active nanomaterials [49].

\section{Specificity and long-term stability of the immunochromatographic strip sensor}

Six common Gram-negative bacteria that also have the LPS structure and two important Gram-positive pathogens were tested to evaluate the specificity of the strip assay. As shown in Fig. 4, the Gram-negative E. coli O157:H7, E. coli O6, Cronobacter sakazakii, Vibrio parahemolyticus, Campylobacter jejuni, Campylobacter coli and Gram-positive Staphylococcus aureus and Listeria monocytogenes did not inhibit the color on the $\mathrm{T}$ line, even at a very high

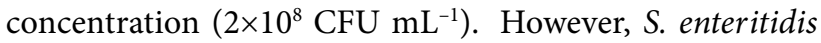
completely inhibited the color on the $\mathrm{T}$ line. These data indicate that the developed strip assay showed excellent specificity within Salmonella and did not react with other common bacteria including non-pathogenic E. coli. Muldoon et al. [50] reported an $\mathrm{O}$ antigen mAb-based immunochromatographic strip and a bacteriophage-based method to eliminate the cross-reaction between Citrobacter spp. and E. coli. In our study no cross-reaction with these bacteria was observed, which may be attributed to the $\mathrm{mAb}$ that specifically recognized the conserved outer core of Salmonella.

In addition, the long-term stability and repeatability of the strip sensor were evaluated. The prepared strips were stored at room temperature with desiccant and the Au NPs labeled LPS $\mathrm{mAb}$ was stored in $0.02 \mathrm{~mol} \mathrm{~L}^{-1} \mathrm{PBS}$ containing $0.02 \% \mathrm{NaN}_{3}$ at $4^{\circ} \mathrm{C}$. Based on our results, the sensitivity and specificity did not changed during six months preservation. This was because the mAb on the NC membrane, which was air-dried and kept in dry environment at $25^{\circ} \mathrm{C}$, was stable and free of the bacteria. On the other hand, adsorbed BSA and mAb on the Au NPs prevented the Au NPs from aggregation and the $\mathrm{NaN}_{3}$ inhibited the growth of bacteria.

\section{Milk sample analysis with the immunochromatographic strip sensor}

To apply the novel strip assay to the detection of Salmonella in a real sample, pure milk was spiked with S. paratyphi $A$, S. typhimurium, S. enteritidis, and S. arizona at a low level (1-5 CFU mL $\left.\mathrm{mL}^{-1}\right)$ and analyzed using the strip after enrichment. Fig. 5 shows that $S$. paratyphi A, S. typhimurium, and $S$. enteritidis completely inhibited the color on the $\mathrm{T}$ line and S. arizona clearly inhibited the color on the T line. Therefore, the four typical strains of Salmonella at a low level in the pure milk sample were detected by visual judgement after $12 \mathrm{~h}$ enrichment. Analysis of these four Salmonella strains with different $\mathrm{O}$ antigens validated the effectiveness of the developed competitive immunochromatographic strip.

Table S2 shows that the results of the analysis are consistent with those of the classic culture-based method. However, the developed strip assay greatly decreased the detec-

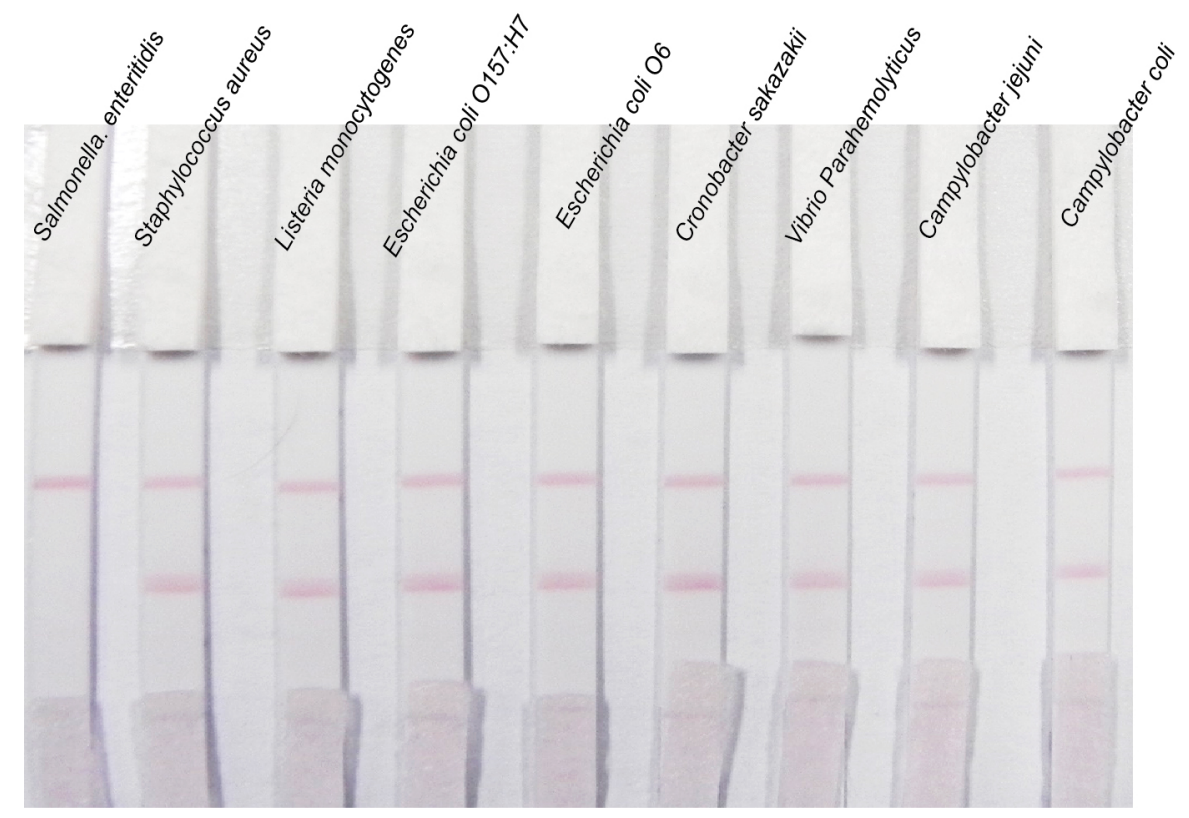

Figure 4 Specificity of the immunochromatographic strip sensor with the Gram-negative and Gram-positive bacteria. 


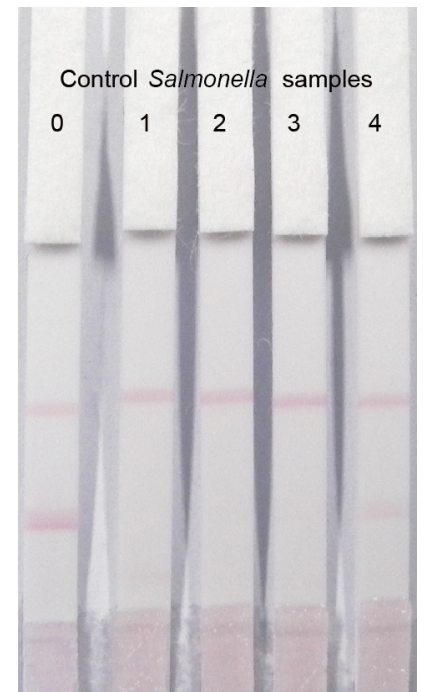

Figure 5 Analysis of Salmonella at low level in pure milk sample after 12 h enrichment: 0, Negative control; 1, S. paratyphiA; 2, S. typhimurium; 3 , S. enteritidis; 4 , S. arizona.

tion time of Salmonella spp. including S. arizona, without the need for complex biochemical confirmation steps, sophisticated instruments, and professional training [9].

\section{CONCLUSION}

In summary, we report a novel competitive immunochromatographic strip sensor based on a genus-specific antiLPS $\mathrm{mAb}$ for the rapid detection of twelve typical strains of Salmonella. Murine mAbs against the conserved outer core structure of Salmonella LPS were produced with LPS-BSA conjugates as immunogens. Based on the heterogeneous conjugate as the coating antigen for the $\mathrm{T}$ line, and the $\mathrm{Au}$ NPs labeled outer core specific $\mathrm{mAb}$ as the detection probe, the innovative competitive immunochromatographic strip was established. Our results showed that $25 \mathrm{ng} \mathrm{mL}^{-1}$ of the $\mathrm{Ra}$ LPS from Salmonella inhibited color on the $\mathrm{T}$ line and the sensitivity based on gray values was at $10^{3} \mathrm{CFU}$ for all the tested Salmonella strains except $S$. thompson $\left(10^{4} \mathrm{CFU}\right)$. The broad cross-reaction in the Salmonella genus and excellent specificity with the other tested Gram-negative and Gram-positive bacteria indicated that this novel strip assay was accurate for the detection of Salmonella at the genus level. In addition, real sample analysis demonstrated that a milk sample contaminated with Salmonella at a low level (1-5 CFU mL ${ }^{-1}$ ) was detected after $12 \mathrm{~h}$ enrichment. The analysis of Salmonella using this strip assay not only saved time, but also simplified the detection which did not require complex biochemical confirmation steps, sophisticated instruments and professional training. Therefore, the novel competitive strip sensor developed in this study is a promising portable and rapid platform for the detection of Salmonella spp. in food and clinical samples.

Received 6 June 2016; accepted 12 July 2016;

published online 18 August 2016

1 Singh J, Sharma S, Nara S. Evaluation of gold nanoparticle based lateral flow assays for diagnosis of enterobacteriaceae members in food and water. Food Chem, 2015, 170: 470-483

2 Zhu D, Yan Y, Lei P, et al. A novel electrochemical sensing strategy for rapid and ultrasensitive detection of Salmonella by rolling circle amplification and DNA-Au NPs probe. Anal Chim Acta, 2014, 846: 44-50

3 Zaki MH, Man SM, Vogel P, et al. Salmonella exploits NLRP12-dependent innate immune signaling to suppress host defenses during infection. Proc Natl Acad Sci USA, 2014, 111: 385-390

4 Yang X, Huang J, Wu Q, et al. Prevalence, antimicrobial resistance and genetic diversity of Salmonella isolated from retail ready-to-eat foods in China. Food Control, 2016, 60: 50-56

5 Fang Z, Wu W, Lu X, et al. Lateral flow biosensor for DNA extraction-free detection of Salmonella based on aptamer mediated strand displacement amplification. Biosens Bioelectron, 2014, 56: 192-197

6 Park S, Kim YT, Kim YK. Optical enzyme-linked immunosorbent assay on a strip for detection of Salmonella typhimurium. Biochip J, 2010, 4: 110-116

7 Yoshida C, Lingohr EJ, Trognitz F, et al. Multi-laboratory evaluation of the rapid genoserotyping array (SGSA) for the identification of Salmonella serovars. Diagn Microbiol Infect Dis, 2014, 80: 185-190

8 Hein I, Flekna G, Krassnig M, et al. Real-time PCR for the detection of Salmonella spp. in food: an alternative approach to a conventional PCR system suggested by the FOOD-PCR project. J Microbiol Method, 2006, 66: 538-547

9 Park SH, Ricke SC. Development of multiplex PCR assay for simultaneous detection of Salmonella genus, Salmonella subspecies I, Salm. Enteritidis, Salm. Heidelberg and Salm . Typhimurium. J Appl Microbiol, 2015, 118: 152-160

10 Shao Y, Zhu S, Jin C, et al. Development of multiplex loop-mediated isothermal amplification-RFLP (mLAMP-RFLP) to detect Salmonella spp. and Shigella spp. in milk. Int J Food Microbiol, 2011, 148: 75-79

11 Liu CC, Yeung CY, Chen PH, et al. Salmonella detection using 16S ribosomal DNA/RNA probe-gold nanoparticles and lateral flow immunoassay. Food Chem, 2013, 141: 2526-2532

12 Zhuang L, Gong J, Li Q, et al. Detection of Salmonellaspp. by a loop-mediated isothermal amplification (LAMP) method targeting bcfD gene. Lett Appl Microbiol, 2014, 59: 658-664

13 Jyoti A, Vajpayee P, Singh G, et al. Identification of environmental reservoirs of nontyphoidal Salmonellosis: aptamer-assisted bioconcentration and subsequent detection of Salmonella typhimurium by quantitative polymerase chain reaction. Environ Sci Tech, 2011, 45: 8996-9002

14 Ma X, Jiang Y, Jia F, et al. An aptamer-based electrochemical biosensor for the detection of Salmonella. J Microbiol Method, 2014, 98: 94-98

15 Jain S, Chattopadhyay S, Jackeray R, et al. Highly sensitive detection of Salmonella typhi using surface aminated polycarbonate membrane enhanced-ELISA. Biosens Bioelectron, 2012, 31: 37-43

16 Kong D, Liu L, Xing C, et al. Sensitive and highly specific detection 
of Cronobacter sakazakii based on monoclonal sandwich ELISA. Food Agricultural Immunol, 2015, 26: 566-576

17 Wang W, Feng M, Kong D, et al. Development of an immunochromatographic strip for the rapid detection of Pseudomonas syringae pv. maculicola in broccoli and radish seeds. Food Agric Immunol, 2015, 26: 738-745

18 Wang W, Liu L, Song S, et al. A highly sensitive ELISA and immunochromatographic strip for the detection of Salmonella typhimurium in milk samples. Sensors, 2015, 15: 5281-5292

19 Chen Y, Xie M. A colorimetric and ultrasensitive immunosensor for one-step pathogen detection via the combination of nanoparticle-triggered signal amplification and magnetic separation. RSC Adv, 2015, 5: 100633-100637

20 Dai F, Zhang M, Hu B, et al. Immunomagnetic nanoparticles based on a hydrophilic polymer coating for sensitive detection of Salmonella in raw milk by polymerase chain reaction. RSC Adv, 2015, 5: 3574-3580

21 Fei J, Dou W, Zhao G. A sandwich electrochemical immunoassay for Salmonella pullorum and Salmonella gallinarum based on a AuNPs $/ \mathrm{SiO}_{2} / \mathrm{Fe}_{3} \mathrm{O}_{4}$ adsorbing antibody and 4 channel screen printed carbon electrode electrodeposited gold nanoparticles. RSC Adv, 2015, 5: 74548-74556

22 Pandey SK, Rishi P, Suri CR, et al. Anodic stripping voltammetry of anti-Vi antibody functionalized CdTe quantum dots for the specific monitoring of Salmonella enterica serovar typhi. RSC Adv, 2015, 5: 88234-88240

23 Kong D, Liu L, Song S, et al. A gold nanoparticle-based semi-quantitative and quantitative ultrasensitive paper sensor for the detection of twenty mycotoxins. Nanoscale, 2016, 8: 5245-5253

24 Wang L, Chen W, Ma W, et al. Fluorescent strip sensor for rapid determination of toxins. Chem Commun, 2011, 47: 1574-1576

25 Wang W, Liu L, Xu L, et al. Gold-nanoparticle-based multiplexed immunochromatographic strip for simultaneous detection of staphylococcal enterotoxin A, B, C, D, and E. Part Part Syst Charact, 2016, 33: 388-395

26 Xing C, Liu L, Song S, et al. Ultrasensitive immunochromatographic assay for the simultaneous detection of five chemicals in drinking water. Biosens Bioelectron, 2015, 66: 445-453

27 Leem H, Shukla S, Song X, et al. An efficient liposome-based immunochromatographic strip assay for the sensitive detection of Salmonella typhimurium in pure culture. J Food Saf, 2014, 34: 239-248

28 Shukla S, Leem H, Kim M. Development of a liposome-based immunochromatographic strip assay for the detection of Salmonella. Anal Bioanal Chem, 2011, 401: 2581-2590

29 Moongkarndi P, Rodpai E, Kanarat S. Evaluation of an immunochromatographic assay for rapid detection of Salmonella enterica serovars typhimurium and Enteritidis. J Vet Diagn Invest, 2011, 23: 797-801

30 Xia S, Yu Z, Liu D, et al. Developing a novel immunochromatographic test strip with gold magnetic bifunctional nanobeads (GMBN) for efficient detection of Salmonella choleraesuis in milk. Food Control, 2016, 59: 507-512

31 Preechakasedkit P, Pinwattana K, Dungchai W, et al. Development of a one-step immunochromatographic strip test using gold nanoparticles for the rapid detection of Salmonella typhi in human serum. Biosens Bioelectron, 2012, 31: 562-566

32 Bautista DA, Elankumaran S, Arking JA, et al. Evaluation of an immunochromatography strip assay for the detection of Salmonella sp. from poultry. J Vet Diagn Invest, 2002, 14: 427-430

33 Yin Y, Liu L, Song S, et al. Development of a highly sensitive icELISA to detect semicarbazide based on a monoclonal antibody.
Food Agric Immunol, 2015, 26: 356-365

34 Guan D, Guo L, Liu L, et al. Development of an ELISA for nitrazepam based on a monoclonal antibody. Food Agric Immunol, 2015, 26: 611-621

35 Frens G. Controlled nucleation for the regulation of the particle size in monodisperse gold suspensions. Nat Phys Sci, 1973, 241: 20-22

36 Wu X, Wang W, Liu L, et al. Monoclonal antibody-based crossreactive sandwich ELISA for the detection of Salmonella spp. in milk samples. Anal Methods, 2015, 7: 9047-9053

37 Li X, Li P, Zhang Q, et al. Multi-component immunochromatographic assay for simultaneous detection of aflatoxin B1, ochratoxin A and zearalenone in agro-food. Biosens Bioelectron, 2013, 49: 426-432

38 Shukla S, Leem H, Lee JS, et al. Immunochromatographic strip assay for the rapid and sensitive detection of $S$. typhimurium in artificially contaminated tomato samples. Can J Microbiol, 2014, 60: 399-406

39 Cho IH, Irudayaraj J. Lateral-flow enzyme immunoconcentration for rapid detection of Listeria monocytogenes. Anal Bioanal Chem, 2013, 405: 3313-3319

40 Zhao Y, Wang $\mathrm{H}$, Zhang $\mathrm{P}$, et al. Rapid multiplex detection of 10 foodborne pathogens with an up-converting phosphor technologybased 10-channel lateral flow assay. Sci Rep, 2016, 6: 21342

41 Ranganathan A, Paradise GA, Hansen CA, et al. Indirect homologous competitive enzyme-linked immunosorbent assay for the detection of a class of glycosylated dihydrochalcones. J Agric Food Chem, 2013, 61: 6964-6970

42 Choi D, Tsang RSW, Ng MH. Sandwich capture ELISA by a murine monoclonal antibody against a genus-specific LPS epitope for the detection of different common serotypes of Salmonella. J Appl Bacteriology, 1992, 72: 134-138

43 Petsch D, Anspach FB. Endotoxin removal from protein solutions. J Biotech, 2000, 76: 97-119

44 Sasaki Y, Tsujiyama Y, Asai T, et al. Salmonella prevalence in commercial raw shell eggs in Japan: a survey. Epidemiol Infect, 2011, 139: 1060-1064

45 Heinrichs DE, Yethon JA, Whitfield C. Molecular basis for structural diversity in the core regions of the lipopolysaccharides of Escherichia coliand Salmonella enterica. Mol Microbiol, 1998, 30: 221-232

$46 \mathrm{Wu}$ W, Li J, Pan D, et al. Gold nanoparticle-based enzyme-linked antibody-aptamer sandwich assay for detection of S. typhimurium. ACS Appl Mater Interf, 2014, 6: 16974-16981

47 Huang P, Tu D, Zheng W, et al. Inorganic lanthanide nanoprobes for background-free luminescent bioassays. Sci China Mater, 2015, 58: $156-177$

48 Zhang Y, Kang Z, Yan X, et al. ZnO nanostructures in enzyme biosensors. Sci China Mater, 2015, 58: 60-76

49 Duan J, Zhan J. Recent developments on nanomaterials-based optical sensors for $\mathrm{Hg}^{2+}$ detection. Sci China Mater, 2015, 58: 223-240

50 Muldoon MT, Teaney G, Li J, Onisk DV, Stave JW. Bacteriophage-based enrichment coupled to immunochromatographic strip-based detection for the determination of Salmonella in meat and poultry. J Food Prot, 2007, 70: 2235-2242

Acknowledgments This work was supported by the National Natura Science Foundation of China (21471068), the National Key Technologies R\&D Program from Ministry of Science and Technology of China (2012BAK08B01), Special Fund for Argo-scientific Research in the Public Interest (201513006), the Natural Science Foundation of Jiangsu Province (BK201501, BK20140003, BE2013613, BE2013611 and CSE11N1310), and the Graduate Innovation Project in Jiangsu Province of China 
(KYLX15_1137).

Author contributions Kuang $\mathrm{H}$ and $\mathrm{Xu} \mathrm{C}$ conceived and designed the experiments. Wang W, Liu L, and Song S performed the experiments. Xu $\mathrm{L}$, Kuang $\mathrm{H}$ and $\mathrm{Zhu} \mathrm{J}$ analyzed the data. Wang $\mathrm{W}$ wrote the paper. Kuang $\mathrm{H}, \mathrm{Xu} \mathrm{L}$, and $\mathrm{Xu} \mathrm{C}$ revised and approved the final version of the paper. All authors reviewed the manuscript.
Conflict of interest The authors declare that they have no conflict of interest.

Supplementary information Supplementary information is available in the online version of this article.

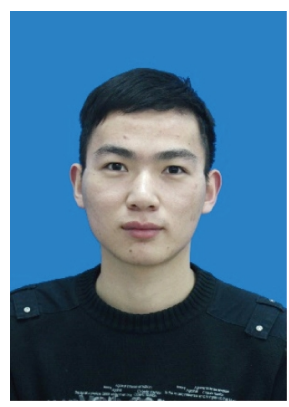

Wenbin Wang is now a PhD candidate at Jiangnan University. His research is focused on the development of monoclonal antibodies and biosensors of foodborne pathogens.

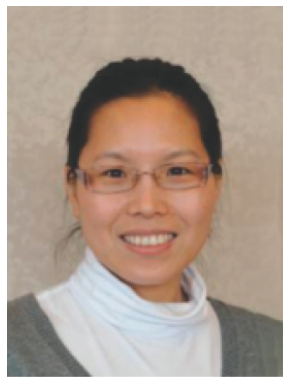

Hua Kuang is a professor of Jiangnan University. She received her PhD degree from China Agricultural University in 2009, and then joined Jiangnan University. Her research areas include nanoparticle assemblies for biosensors.

\section{基于菌属特异性抗体的金标试纸传感器同时检测12种沙门氏菌}

王文涁, 刘丽强, 宋珊珊, 徐丽广, 匡华”, 朱建平, 胥传来

摘要 沙门氏菌属是全球关注的重要食源性致病菌之一. 本文以沙门氏菌属特异性脂多糖抗体与胶体金纳米粒子进行偶联, 并进行固相化, 装配了适合于快速、可视化分析的金标试纸传感器. 裸眼观察下, 金标试纸条可以识别浓度低至 $25 \mathrm{ng} \mathrm{mL}^{-1}$ 的沙门氏菌属脂多糖. 结合灰 度扫描分析, 金标试纸对受试的 12 种沙门氏菌的敏感性可达到 $10^{3}$ 菌落形成单位(CFU). 对牛奶样品进行 $12 \mathrm{~h}$ 的富集孵育, 该金标试纸条对 沙门氏菌的检测灵敏度可达 1 个CFU. 金标试纸传感器无需复杂的前处理过程和专业设备, 操作简单, 有效地提高了致病菌的检测效率. 